\title{
Tres visiones del concepto de identidad cultural en la reflexión acerca del arte latinoamericano
}

\section{Três visões do conceito de identidade cultural no pensamento sobre arte latino-americana}

\section{Three visions of the concept of cultural identity in the study of the Latin American art}

\author{
Tomás Ejea Mendozai
}

\author{
Palabras clave: \\ Identidad \\ Arte \\ Latinoamérica \\ Crítica artística
}

Resumen:

En este texto a partir de la reflexión en torno a la categoría de identidad, se sondea la posibilidad de utilizar dicha categoría para abordar analíticamente lo que ha sido el discurso de los críticos, comentaristas e investigadores de arte en América Latina durante las últimas décadas. De entrada habría que aclarar que el concepto de identidad, como muchos conceptos que se utilizan en la reflexión y análisis de los procesos creativos y humanísticos, es un concepto polisémico, en el sentido de que no todos los que lo utilizan concuerdan con la definición de su significado. Así entonces, en este trabajo se partirá de contraponer tres visiones del concepto de identidad cultural: la visión ilustrada; la sociologista y la posmoderna, que están, cada una de ellas, fuertemente relacionadas con tres tipos de conceptos de sujetos sociales. A partir de ello se propondrá su posible aplicación al pensamiento que ha reflexionado sobre el trabajo de las artes y la cultura en Latinoamérica. 


\begin{abstract}
Resumo:
Neste texto, a partir da reflexão sobre a categoria de identidade, focase a capacidade de usar essa categoria para abordar analiticamente o que tem sido o discurso dos críticos, comentadores e investigadores de arte na América Latina durante as últimas décadas. De início, deve ficar claro que o conceito de identidade, como muitos conceitos utilizados na reflexão e análise dos processos criativos e humanistas, é um conceito polissêmico, no sentido de que nem todos os que o usam concordam na definição de seu significado. Portanto, este trabalho será baseado em três visões que se opõem no conceito de identidade cultural: a visão ilustrada; a sociológica e a pós-moderna, que são, cada uma delas, fortemente associadas com três tipos de conceitos de sujeitos sociais. A partir disto, propõe-se possível aplicação ao pensamento que tem refletido sobre o trabalho das artes e sobre a cultura na América Latina.
\end{abstract}

\section{Palavras chave:}

Identidade

Arte

América Latina

A crítica de arte

\section{Keywords:}

Identity

Art

Latin America

Art criticism

\section{Abstract:}

In this paper is explored the possibility of using the analytically category of identity to address what has been the discourse of critics, commentators and researchers of art in Latin America during the last decades. Should be made clear that the concept of identity, as many concepts used in the reflection and analysis of the creative and humanistic processes, is a polysemic concept, in the sense that not all who use it consistent with the definition of its meaning. So, this work will be based on three visions oppose the concept of cultural identity: the illustrated vision; the sociologist vision and postmodern vision, which are, each one, strongly associated with three types of concepts of social subjects. From this, its application is proposed to analyze the thinking about the activity of arts and culture in Latin America. 


\section{Tres visiones del concepto de identidad cultural en la reflexión acerca del arte latinoamericano}

\section{Introducción}

Este texto de carácter teórico parte de la reflexión en torno a la categoría de identidad cultural. Sondea la posibilidad de utilizar dicha categoría para abordar analíticamente lo que ha sido el discurso de los críticos, comentaristas e investigadores de arte en América Latina durante las últimas décadas.

Primeramente habría que aclarar que el concepto de identidad, como muchos conceptos que se utilizan en la reflexión y análisis de los procesos creativos y humanísticos, es un concepto polisémico, en el sentido de que no todos los que lo utilizan concuerdan con la definición de su significado. Así entonces, en este trabajo se contraponen tres visiones del concepto de identidad cultural que así mismo cada una de ellas está relacionada con tres modalidades de caracterización del sujeto social. En este sentido, se plantean los conceptos de identidad cultural que se derivan de sendas visiones de la constitución del sujeto social: la visión ilustrada, la visión sociologista clásica y la visión denominada posmoderna. A partir de ello, se esbozará la utilización de estas visiones como sustento de análisis de algunos textos de teoría y de crítica de las artes plásticas que se han producido en Latinoamérica en las últimas décadas.

Como primer punto de este artículo se desglosan brevemente las tres acepciones del concepto de identidad que se derivan del modo de concebir al sujeto social. En primer lugar, el sujeto ilustrado que tiene una fuerte relación con la conformación de la identidad esencialista. En segundo lugar el sujeto sociológico clásico que se encuentra en un punto intermedio entre el planteamiento de identidad esencialista y de identidad pluralista o posmoderna. Finalmente, el sujeto visto desde el posmodernismo de identidad pluralista.

Primeramente, el concepto de identidad basado en la idea de un sujeto ilustrado está basado en la concepción de la persona humana como totalmente centrada, individualmente unificada, dotada con las capacidades de razón, conciencia y acción. Su "centro" consiste en un ser, núcleo interno que emerge primero cuando el sujeto nace, y se despliega en él permaneciendo esencialmente él mismo -continua e idénticamente con el mismo- a través de la existencia del individuo. Esta acepción de la identidad, tiene un fuerte rasgo esencialista y pensaría a los sujetos como seres pre-constituidos y difícilmente alterables en su identidad a lo largo de los procesos en los que se desenvuelve. En una concepción como ésta, se partiría de la suposición de que existen sujetos con una naturaleza inmutable que mantienen una mentalidad y una estrategia rígidas con independencia de las influencias de diversa índole a las que se ven sometidos a lo largo de su desenvolvimiento (GUTIÉRREZ, 2001). Desde este punto de vista, el centro esencial del ser, sería en primer término la identidad de la persona, posteriormente sería la del grupo, después la del país, y así sucesivamente cada vez de manera más amplia.

En segundo lugar, la noción de sujeto sociológico clásico refleja la creciente complejidad del mundo moderno y la conciencia de que el núcleo del sujeto no es autónomo y auto suficiente, si no que éste se conforma en relación con los otros significantes, que mediatizan los valores del sujeto, significados 
y símbolos -la cultura- del mundo que habita. Es una concepción interactiva de la identidad y del ser formada por la interacción entre el ser individual y la sociedad. Bajo esta perspectiva, el sujeto tiene una esencia que es "el yo real", pero éste está conformado y modificado en un continuo diálogo con los mundos culturales externos a él y las identidades que esos mundos ofrecen. Desde este punto de vista la concepción sociológica de identidad, elimina la distancia entre el dentro y el afuera -entre el mundo personal y el mundo público. El hecho de que nosotros mismos nos proyectemos en esas identidades culturales, al mismo tiempo internalizando sus significados y valores, haciéndolos parte de nosotros, ayuda a alinear nuestro sentir subjetivo con los lugares objetivos que ocupamos en el mundo social y cultural. La identidad, entonces ata al sujeto con la estructura. Estabiliza ambos mundos que habitamos, el mundo subjetivo y el mundo cultural, haciendo ambos recíprocamente más unificados y predecibles.

Por último, en tercer lugar, la noción de sujeto posmoderno, conceptualizado como no teniendo identidad fija, esencial o permanente. La identidad es moldeable: formada y transformada continuamente en relación con las maneras en que somos representados y nombrados en el sistema cultural que nos rodea. Es históricamente, y no biológicamente, definida. El sujeto asume diferentes identidades en diferentes tiempos, identidades que no están unificadas alrededor de un ser coherente. Dentro de nosotros existen identidades contradictorias presionando en diferentes direcciones, así nuestras identidades están continuamente siendo cambiadas. Si sentimos que tenemos una identidad unificada desde el nacimiento a la muerte, es solamente porque nosotros mismos construimos una historia reconfortante o narrativa de nuestro ser acerca de nosotros. La identidad como algo unificado, completo, seguro y coherente es solamente una fantasía. En lugar de ello, en la medida en que el sistema de significados y de representación cultural se multiplica, somos confrontados por una perturbadora y fugaz multiplicidad de posibles identidades, con cada una de las cuales nos podríamos, al menos temporalmente, identificar.

En este sentido, cabría citar el planteamiento que realiza Chantal Mouffe: "La historia del sujeto es la historia de sus identificaciones, y no hay una identidad oculta que deba ser rescatada más allá de la última identificación. Hay por tanto, un movimiento constante: Pero esto es posible porque la estabilidad no está dada de antemano, porque ningún centro de subjetividad precede a las identificaciones del sujeto" (MOUFFE, 1999, p. 111). Por eso no hay ninguna posición de sujeto cuyos vínculos con otras estén asegurados de manera definitiva y, por lo tanto, no hay identidad social que pueda ser completa y permanentemente adquirida.

Las identidades culturales de los sujetos desde esta visión es efímera, entonces no responden a ningún tipo de predeterminación o de inmanencia, sino que son producidas a partir de interacciones históricas, y por ende cambiantes, en las que se encuentran en juego valores, normas, conocimientos y expectativas que pueden ser asumidos o rechazados.

Esta última acepción del concepto de identidad está fuertemente relacionada con el carácter de constante cambio que tiene la globalización y la modernidad y su impacto en la identidad cultural.

Por otra parte, en las sociedades tradicionales el pasado es venerado y los símbolos son valorados porque contienen la experiencia perpetua de las generaciones. Aquí, en este tipo de 
sociedades la tradición es una manera de manejar el tiempo y el espacio que inserta cualquier actividad o experiencia particular en una continuidad de pasado, presente y futuro, los cuales son estructurados por el criterio de la recurrencia de las prácticas sociales.

\section{Tres visiones de la identidad cultural en el arte latinoamericano}

En este sentido, se puede afirmar que existen tres grandes vertientes de formas de ver la identidad. Aquella que enraizada en el sujeto ilustrado plantea la existencia de una identidad esencial. Esta visión habla explícitamente sobre la problemática de la identidad en el arte latinoamericano y lo relaciona con un contexto más amplio, esto es, aunque su discurso se centra en la cuestión del arte y la cultura, no se limita a ello y realiza el planteamiento del ser latinoamericano en un contexto amplio. Esta corriente tuvo una fuerza predominante en América Latina durante todo el siglo XX. Mantuvo este predominio hasta que comienza a dar paso a una visión del segundo tipo, la visión de la identidad como sujeto sociológico, a partir de los años cincuenta y paulatinamente fue ganando terreno hasta convertirse en una posición mayoritaria en los años setenta. Sobre todo a partir de la fuerte influencia que tuvieron los estudios que abordaban el campo del arte a partir de una visión antropológica o sociológica. A partir de ello se comenzó a conformar una tercera visión de identidad, la que plantea el sujeto llamado posmoderno que se integra a partir de los años ochenta y que va adquirió una presencia cada vez mayor en los últimos años.

Ejemplo de la primera, para efectos de este trabajo, serán los planteamientos de Octavio Paz, algunos textos de Juan Acha y Orlando Hernández. Ejemplos de la segunda será el planteamiento de Marta
Traba, Gustavo Buntinx, Federico Morais, entre otros, que hablan sobre la resistencia. Finalmente para el tercer grupo me basaré básicamente en los planteamientos de Mari Carmen Ramírez y Néstor García Canclini.

\section{La visión ilustrada del sujeto y la iden- tidad sustancial}

Al respecto en primer lugar habría que mencionar que la visión ilustrada del sujeto tiene una fuerte relación con una idea sustancialista de la identidad. Debido a que plantea como idea fundamental en que este tipo de discursos parten de la idea de que existe una sustancia en lo profundo de la vida cultural de determinado grupo social. En este sentido al hablar del arte latinoamericano se estaría en la búsqueda de las características de esa identidad. Lo que primeramente salta a la vista es que en estos discursos la idea de identidad como una serie de características en común de lo latinoamericano se dan como un hecho, esto es, se parte del punto de partida ya sea explícita o implícitamente que lo latinoamericano existe como tal. La problemática entonces para la crítica, los comentaristas, investigadores, creadores y demás participantes en el arte latinoamericano, en mayor o menor medida, como compromiso y responsabilidad, es el elaborar y desarrollar los valores propios de esa latinoamericanidad. En esta visión mencionaré tres tipos de discursos que si bien, a mi juicio, comparten esta visión de sujeto tienen importantes diferencias.

El primer discurso es el de Octavio Paz, en la medida que su pensamiento constituyó uno de los más influyentes visiones en el mundo de la plástica y la literatura en las últimas décadas del siglo pasado. Aunque muchos de sus textos se refieren a la identidad mexicana, resulta, sin pretender hacer afirmaciones gratuitas, que su concepción acerca de la identi- 
dad se puede aplicar al planteamiento que se presenta en el arte latinoamericano.

Desde su perspectiva, los países de Latinoamérica “... por la historia y la cultura pertenecemos a Occidente, no a ese nebuloso Tercer Mundo de que hablan los economistas y los políticos. Somos un extremo de Occidente, un extremo excéntrico, disonante" de tal manera que "(en el campo artístico) desde el siglo XVIII hemos bailado fuera del compás, a veces contra la corriente y otras, como en el periodo modernista, tratando de seguir las piruetas del día" esto se debe según el poeta a que "... lo que nos faltó sobre todo fue el equivalente de la llustración y de la filosofía crítica. Allí está la gran ruptura; allí donde comienza la era moderna comienza también nuestra separación... no conocemos la crítica, en el sentido recto de la palabra." (PAZ, 1977, p. 24).

Así mismo podemos ver que con respecto a la pintura, en su célebre artículo acerca de Rufino Tamayo y la influencia que en el tiene la escultura prehispánica plantea que “...el arte popular había ya fertilizado su imaginación y la había preparado para aceptar y asimilar el del antiguo México. No obstante, sin la estética moderna ese impulso inicial se habría disipado o habría degenerado en mero folklore y decoración". (Idem, p. 365). Como podemos ver, aquí lo valioso en la pintura de Tamayo es el lenguaje acorde a la estética moderna, la cual está relacionada con los movimientos europeos y norteamericanos, por el otro lado, lo autóctono lo precolombino no es más que algo que puede degenerar, un mero "folklore" o una "decoración".

Esta visión de Paz está dada desde su escrito El laberinto de la soledad, trabajo por demás influyente en la creación artística y literaria de México y América Latina y en la cual es clara esta visión ilustrada del sujeto, donde se hace patente la idea de que todo aquello que no se adapte a la racionalidad occidental tal como es definida en la metrópoli estaría condenado a la soledad: "Sin los artistas modernos de Occidente, que hicieron suyo todo ese inmenso conjunto de estilos y visiones de la realidad y lo transformaron en obras vivas y contemporáneas, nosotros no habríamos podido comprender y amar el arte precolombino" (Idem, p. 363). De ahí la idea de que lo que no está integrado a occidente es incompleto, desesperado o solitario, como el mismo dice: "nuestros pueblos viven entre los espasmos de la rebeldía y el estupor de la pasividad" (Idem, p. 24).

En este sentido, es una construcción de la identidad donde la referencia principal es el otro, que nos mira y nos determina como los dominados desde una posición de dominadores. Esta posición es aceptada implícitamente y lo que queda es en parte auto lamentarse. Esto es, a los países latinoamericanos les ha faltado "...la palabra racional, la palabra crítica... en contra del monólogo y el griterío" (Ibidem), en parte integrarse pero sobre todo buscar seguir el camino que occidente ha planteado. La idea que occidente tiene de progreso hay que aceptarla por que se parte de que es la idea de progreso en singular puesto que occidente ha llegado a constituirse como la avanzada del sujeto iluminado, -"somos un extremo de Occidente"- donde ilustración se corresponde con civilización ${ }^{i i}$. Nos queda pues como pueblos latinoamericanos no avanzados intentar por todos los medios en ponernos en sincronía con esa avanzada civilizatoria: Europa y Norteamérica.

Como se puede ver, de cierta manera estamos en presencia de una versión actualizada de construir al buen salvaje. A éste le queda como camino, a partir de su identidad sustancial mestiza -en parte occidental y en parte primitiva- 
o bien, actualizarse en la competencia que se desarrolla en la metrópoli y ajustarse al canon propuesto por ella o continuar en la barbarie y la ausencia de civilización. Dentro de esta perspectiva se glorifica lo autóctono pero solamente en la medida que da elementos para integrarse a lo moderno. Lo autóctono en sí mismo, sin su purificación o su pulimento para adaptarse al canon que instaura la metrópoli no tiene valor, puesto que se queda en lo primitivo. Por supuesto que estancarse en ese estado primitivo, ante el ímpetu del arte moderno, lo condena a estar aislado y ser condenado por la luminosidad del sujeto ilustrado. Esta condena lleva al arte primitivo a estar en un proceso de soledad y en todo caso, cuando ha alcanzado cierta conciencia de su ser primitivo lo lleva a un proceso de constante lamentación.

En el segundo planteamiento a analizar, tenemos las ideas que propone Juan Acha. Su pensamiento es complejo y su contribución a la crítica y al estudio del arte latinoamericano es muy valiosa, sin embargo, no se deja de percibir en algunos de sus textos esta forma de concebir la idea de identidad como algo dado de manera preexistente. Desde su punto de vista no se necesita encontrar lo que es la latinoamericanidad, ni como un proceso de construcción social, ni como una búsqueda artística. La existencia de lo latinoamericano se da como un hecho, como los elementos que nos unen y nos conforman como un ser social, sin embargo y de ahí lo radical de su planteamiento "No es que estemos en la búsqueda de nuestra identidad sino en la búsqueda de la auto concientización de nuestra identidad, o sea la búsqueda de conceptos para comprender nuestra identidad,". La idea de que debemos -como latinoamericanos que somos- de encontrar el camino de la conceptualización ya que "... nos falta construir modelos conceptuales que comprendan y nos hagan compren- der lo que somos y a la vez el hecho de que queremos ser otros" ya que "... existimos de una manera muy particular, de una manera muy latinoamericana" de ahí que el ideal el como las cosas deberían de ser se convierte en algo fundamental a alcanzar y el parámetro implícito para medir lo que "nosotros somos" está dado por los alcances y logros de los países modernos (ACHA, 1977, p. 27). En esta ardua e irremediablemente infructuosa tarea de llegar a los niveles de desarrollo de los países avanzados el voltear a ver "nuestro estado de cosas" nos lleva forzosamente a una sensación de autocompasión y auto lamentación pues no somos capaces de estar al nivel que deberíamos, en el que si se encuentran los "otros" entendidos estos como los que están en un etapa evolutiva más avanzado del proceso de ilustración: "No se puede acelerar a voluntad la realidad evolutiva, dice Acha, sino de acuerdo con las favorables condiciones económicas y educativas, políticas y tecnológicas de nuestros respectivos países... es ahí donde resalta el abismo entre nuestros ideales (lo que deben ser las cosas) y la cruda realidad evolutiva" (ACHA, 1994, p. 1031).

En este tipo de discurso aparece con toda claridad la utilización del nosotros como algo dado de antemano de manera apriorística. Entramos entonces en un código jerarquizante en que la ordenación está dado por el que establece las normas y valores. Para decirlo con Foucault todos los órdenes y los discursos que sustentan el poder, así en plural, los discursos por que no es únicamente uno, son multiplicidad de discursos que se entrelazan para conformar un conjunto de reglas, un orden de elementos del sistema, y este orden, dice Foucault, tiene formas y estrategias. (FOUCAULT, 1968)

Un tercer ejemplo de esta perspectiva es la que presenta el texto de Orlando Hernández Mapa (incompleto) de Por 
América (HERNÁNDEZ, 2000), en el que se aboca al estudio de la obra Por América de Juan Francisco Elso. En este texto podemos ver que la piedra angular de toda su argumentación está dada en una visión sustancialista de la identidad latinoamericana. Implícitamente se plantea que la identidad latinoamericana cultural es básicamente la libertad y el prócer de esa libertad es José Martí, ahora, con el régimen cubano comunista, se ha dado una traición a esa principio libertario, por tanto el gobierno y la política comunista son un atentado contra ese principio libertario de ahí la importancia de la obra de Elso como un reclamo en contra de la represión y la censura del régimen y según Hernández, un grito a favor de la libertad latinoamericana.

El texto de Hernández desde sus primeras páginas nos presenta una clara idea implícita de identidad latinoamericana. Aunque en términos explícitos es bastante ambiguo y metafórico ya que a veces lo americano se identifica con lo latinoamericano y por lo tanto América como lo latinoamericano se contrapone a los Estados Unidos y a lo Europeo. Bajo esta perspectiva realiza un reproche a los artistas que fuerzan el latinoamericanismo en sus obras "que ven a América y a lo americano como un pretexto para vender a Europa o a Estados Unidos las postales exóticas de nuestra maltratada y gloriosa identidad" (HERNÁNDEZ, 2000 , p. 201). A partir de lo cual, pasa a enaltecer las glorias de los héroes "americanos": Martí, Bolívar, Sucre, San Martín, Hidalgo, Zapata, Che.

Esto queda claro cuando al afirmar que: "la principal intención de la obra parece ser la de acercarnos de manera directa, inmediata, a su figura (de Martí) a lo que fue Martí para nosotros los cubanos y para toda América" (Idem, p. 205). Amén de lo mencionado anteriormente acerca de la identificación de América con Latinoamérica queda claro la utilización nuevamente del nosotros como un todo previamente dado, y por lo tanto, ambiguo, etéreo y sobre todo, indefinido.

Posteriormente, ya avanzado el texto, podemos ver que se repite esta idea cuando, refiriéndose al contenido simbólico del machete considerado como arma en la escultura de Elso, afirma: "Es muy dudoso que esta figura hecha por Elso pueda reducirse a simbolizar un deseo retrospectivo de venganza anticolonialista. Es, debe ser, mucho más. Todas nuestras necesidades y aspiraciones como cubanos, como americanos, como seres humanos, parecen hallarse expresadas, sintetizadas en este instrumento y este gesto." (Idem, p. 225) Otra vez podemos ver como la identificación de lo cubano con lo americano resulta natural en su razonamiento, pues lo americano en cuanto que latinoamericano incluye a lo cubano como una parte de este continente que por su carácter y esencia es un todo conjunto e integrado que representa además una esencia que retoma lo mejor del ser humano y de ahí la posibilidad de hacer una identificación en el concepto de latinoamericano: lo cubano, lo americano y lo humano.

Como podemos ver, si bien existe una característica que une este texto con los dos textos anteriormente mencionados, Paz y Acha, en concebir la identidad desde un punto esencialista y a partir del punto de vista del sujeto ilustrado, en el texto de Hernández tenemos una importante diferencia con ellos. La ilustración que se requiere para el encuentro de la identidad en los textos de Paz y Acha está fuertemente ligada con una ilustración alimentada por lo racional y por la cultura moderna. Por otra parte la ilustración de la que habla Hernández en Martí pero sobre todo en Elso esta dada, no por la ilustración, sino más bien por la iluminación que hace de su obra artística 
"un discurso moral, filosófico, de honda raíz existencial y de un profundo contenido religioso" esto es, para este autor la obra de Elso es "un extraño y silencioso sermón que expone una compleja parábola sobre la salvación de nuestro espíritu." (Idem, p. 225).

Entonces, si la salvación de nuestra cultura según Paz está en el encontrar los caminos que nos permitan no ser extraños a occidente para no vernos condenados a estar perdidos en un laberinto de soledad, para Hernández nuestra salvación está dada en las obras artísticas como la de Elso en la búsqueda de una espiritualidad que nos restablece nuestra identidad "que se ha encontrado en constante peligro".

\section{La visión sociológica del sujeto}

La visión sociológica del sujeto hace que el concepto de identidad tenga semejanzas con la anterior, la visión ilustrada, pero también mantiene diferencias que incluso la llegan a contraponer de manera muy clara. En primer término en esta visión se acepta, y de ahí su semejanza con la anterior, al concepto de identidad del arte latinoamericano como algo dado de manera preexistente, pero se plantea, y esta es lo que las diferencia, que el problema al que hay que enfrentarse no es de buscar, redefinir o conceptualizar a la identidad, sino que de lo que se trataría es de discutir los problemas realmente importantes: ¿Cuál debe ser nuestra actitud frente a la cultura dominante que nos coarta y nos limita como latinoamericanos? En ese sentido, ya no sería necesario plantearse el dilema de nuestra identidad cultural y artística en especial sino más bien cuestionarnos sobre el camino a tomar a partir de una disyuntiva: integrarse o resistirse.

El concepto de identidad entonces como podemos ver bajo esta visión, ya no está encausado en la necesidad de su discusión o su conceptualización, sino que deja implícito y se le da una respuesta indirecta: no necesitamos buscar o discutir ¿qué somos como latinoamericanos? y por tanto, no es necesario plantear ¿qué es nuestro arte?, sino que debemos poner en la mesa de discusión preguntas tales como ¿cómo nuestro arte se subordina a los cánones impuestos por la metrópoli? y ¿cómo se establecen los mecanismos para adaptarnos a ellos? o, en su caso, ¿cómo podemos crear espacios para resistirnos a ellos?. Esta posición la podemos ver en los planteamientos de Marta Traba cuando afirma "Yo creo que deberíamos cambiar el tema de la identidad por otra cosa" (TRABA, 1977, p. 45). De ahí que desde los años setenta proponga la necesidad de dar un reconocimiento a los artistas que, desde su punto de vista, representan esa resistencia: Torres García, Matta, Szyszlo, Morales, Cuevas. (Idem, p. 40)

En este mismo tenor tenemos las afirmaciones que hace el propio Fernando de Szyszlo al respecto en que su posición es por demás elocuente llevando esta visión sociologista hasta un punto muy radical cuando afirma:

El artista latinoamericano ha vivido la misma circunstancia general, con las inevitables diferencias de época y situación que los artistas de todos los tiempos y todas las latitudes que no habitan en la metrópoli... el artista de provincia, el artista marginal padeció siempre una situación colonial que, política, social y culturalmente se le imponía desde las capitales... (SZISZLO, 1977, p. 34).

Como puede verse, bajo esta perspectiva, que adquiere una gran relevancia en los estudios acerca del arte latinoamericano a partir de los años setenta, vemos un planteamiento de identidad implícita, 
en que la otredad - lo europeo y lo norteamericano -, y por lo tanto, su opuesto, lo que "nosotros somos", está definido en términos de la relación social y política concreta en un momento y en un espacio histórico determinados. Esta visión sociologista, no está por demás reiterarlo, se opone a la visión ilustrada, mencionada en el apartado anterior, en que esta última está fundada en la idea de una identidad dada más que por una relación de subordinación económica, política y por tanto, cultural y artísticamente, por una necesidad de ilustrarnos y llegar a tener un arte como lo marca las tendencias producidas en la metrópoli.

Bajo la perspectiva de la mirada del sujeto sociológico, podemos encontrar una importante cantidad de trabajos en la literatura de estudios del arte en Latinoamérica, sobre todo los que utilizan el concepto de identidad entendido como un proceso social, tal es el caso, entre otros, del texto "El indio alfarero como construcción ideológica variaciones sobre un tema de Francisco Laso" de Gustavo Buntinx (BUNTINX, 1994, p. 69102) o "Imágenes e identidades: Europa y América" de Georges Roque (ROQUE, 1994, p. 1017-1030) o "La puesta en escena internacional del arte latinoamericano: montaje, representación" de Nelly Richard. (RICHARD, 1994, p. 1011-1016)

Una posición bastante radical del concepto de identidad ligada a esta visión sociológica del sujeto está dada por Federico Morais, El parte del principio de que la problemática acerca de la identidad del arte latinoamericano es una discusión impuesta desde el exterior: "Por lo general, la mención de América Latina va acompañada de la cuestión de nuestra identidad. Es decir, fueron ellos, los euronorteamericanos, quienes nos formularon a nosotros la pregunta: ¿quiénes somos nosotros, latinoamericanos?" (MORAIS, 1990, 5). Después pasa a plantear las razones de porqué el discurso de nuestra identidad está dado por la metrópoli al decir: "pregunta que, naturalmente, nunca se hicieron a sí mismos, porque en su autosuficiencia se consideran únicos, por encima de toda sospecha". De ahí Morais llega a la idea que nos interesa rescatar y que da cuerpo sustantivo a esta visión sociológica de identidad: "Es necesario superar tanto la "neurosis de la dependencia"... como la "neurosis de la identidad." (Ibidem)

En este texto, que si bien polemiza en ciertos puntos nodales con la posición de Marta Traba, no deja de tener una visión sociológica de la identidad, Morais llega a un posicionamiento muy radical al respecto: no es la función del arte latinoamericano contemporáneo tener una posición de resistencia frente a la metrópoli, sino más bien, una posición liberadora. Esto lo podemos ver en su texto cuando afirma: "A pesar de la vehemencia verbal, la resistencia de Traba sugiere pasividad. O más que eso, el mantenimiento de cierto tipo de arte puede corresponder a una especie de inmovilismo político y social, o de subdesarrollo artístico" y a pesar de que acepta los méritos de la posición de Traba, pues tiene "el mérito enorme de haber sido una de las primeras en manejar un concepto global y abarcador sobre el arte latinoamericano" concluye con una tesis en su contra "Claro, no estoy de acuerdo con esta visión apocalíptica que Traba tiene del arte de vanguardia". (Ibidem) Para Morais, a diferencia de Traba, el arte de vanguardia juega un papel muy importante, en la liberación del arte latinoamericano, incluso citando a Ferreira Gullar concluye:

Necesitamos la industria y el knowhow que ellos tienen (se refiere a las cultura euro-norteamericana), pero con esa industria y eso know-how, que necesitamos para liberarnos, viene la dominación. Así, lo nuevo es para no- 
sotros, contradictoriamente, la libertad y la sumisión. Por eso mismo es que la lucha por lo nuevo, en el mundo subdesarrollado, es una lucha antiimperialista. (Idem, p. 17)

En conclusión, Morais plantea al arte de vanguardia latinoamericano como una posibilidad liberadora, mientras que por su parte, Traba, considera que el arte latinoamericano debe elaborar un arte figurativo o ligeramente abstracto para resistir al arte de vanguardia proveniente de los grandes circuitos comerciales que en su voraz mercantilismo convierte al arte en un "verdadero circo".

Bajo esta perspectiva resulta muy interesante el texto de Andrea Giunta, Strategies of Modernity in Latin America, (GIUNTA, 1966) por que en él se expone, bajo la conceptualización de lo que yo he llamado en este ensayo la visión de identidad del sujeto sociológico, tres movimientos artísticos que han significado otras tres tantas estrategias de oposición del arte latinoamericano a la imposición del canon artístico euro-norteamericano establecido por la modernidad y de las cuales hablaré a continuación.

La primera estrategia a la que se refiere es a la estrategia del tragar, refiriéndose al movimiento de la Antropofagia del Brasil en los años veinte de Tarsila do Amaral y Mario de Andrade cuando afirma: "Pocas imágenes son tan exitosas como ésta del tragar: comerse al hombre blanco, devorándolo y digiriéndolo." (GIUNTA, 1966, p. 55) La idea es oponer al "buen salvaje", construido por el imaginario colonizador, la idea brutal y radical del "salvaje caníbal". Este caníbal como dice Haroldo de Campos es un antologista: "Solamente se come a aquellos enemigos que considera de valor, se come su proteína y el tuétano de sus huesos, para obtener energía y renovar sus fuerzas naturales, lo demás, lo tira a la basura." (Idem, p. 57)
La segunda estrategia a que se hace mención en este texto es la estrategia del mapa invertido que se refiere al movimiento La escuela del sur de Joaquín Torres-García que se resume en el texto "... Nuestro norte es el sur. No debe haber norte para nosotros, excepto en oposición a nuestro sur". El interés de Torres era el fundar una escuela de la plástica que generara un arte popular, monumental, metafísico y ritual y en este sentido voltea a ver al arte Inca, de esta manera, la propuesta de Torres, según Giunta, lo llevaría a plantear la idea de invertir el mapa de generación del arte moderno y "hacer de América la medida del universo." (Idem, p. 59)

La tercera estrategia, establece Giunta, es la que llama la estrategia de la apropiación de la apropiación en ella se refiere al trabajo artístico de Wilfredo Lam. Según ello, Lam propone apropiarse de las formas y la estructura del cubismo, el cual, a su vez se había apropiado de las formas y estructuras del arte primitivo para con ello como él mismo lo dice: "tomar el arte africano y hacerlo operar en su propio mundo, en Cuba. Yo necesitaba expresar en mi obra energía combativa, la protesta de mis ancestros". (Idem, p. 61). En este sentido se plantea que Lam quería una rebelión basada en la reivindicación de la mezcla de la cultura. Esta posición estaría fundada en dos perspectivas: la consolidación del campo artístico de Latinoamérica y el retomar la vanguardia Europea.

En este sentido, es que Andrea Giunta plantea que existen estas estrategias que implicaban ante todo una inversión ideológica de los valores artísticos. Devorar, invertir y reapropiarse de los elementos culturales para construir un discurso propio de carácter subversivo que conforman una construcción plástica "como parte de un programa de la liberación de la cultura". 
En estos planteamientos expuestos, Traba, Giunta, Morais, la legitimidad se encuentra definida fundamentalmente como un acto de fuerza, en contra de la imposición de los cánones euro-norteamericanos, por la presencia del arte latinoamericano. Entonces, el arte latinoamericano puede tener una posición de reconciliación, por un lado, con sus condiciones sociales y económicas y, por el otro, con sus tradiciones estéticas, ya sea como resistencia o como liberación o como cualquier otra opción de carácter subversivo.

\section{La visión posmodernaiii}

La visión del sujeto posmoderno, comienza a tener una fuerte presencia en la reflexión teórica cultural a partir de los años ochenta en diversas disciplinas sociales: la sociología, la antropología y los estudios sobre la creación y la cultura. Su acepción de la identidad como parte de la visión posmoderna del sujeto tiene un fuerte carácter pluralista como se mencionó en páginas anteriores y esta fuertemente imbricado con la problemática de la modernidad.

Este tercera acepción de la identidad tiene una relación importante con las distintas perspectivas del conocimiento y la crítica que plantean la existencia de una modernidad que ha traído consigo una etapa o un momentum posterior a ella, ya sea, según el matiz que cada perspectiva le adhiera, de superación o máximo desarrollo de degeneración corrupta. La problemática en torno a lo posmoderno se encuentra imbricada en torno a los conceptos de modernidad, globalización, mestizaje e hibridación. En este sentido García Canclini afirma lo siguiente: “... entiendo por hibridación procesos socioculturales en los que estructuras o prácticas discretas, que existían en forma separada, se combinan para generar nuevas estructuras, objetos y prác- ticas. Cabe aclarar que las estructuras llamadas discretas fueron resultado de hibridaciones, por lo cual no pueden ser consideradas fuentes puras." (GARCÍA CANCLINI, 2003, p. III)

Otra posición muy cercana a este planteamiento es la que hace Serge Gruzinsky al respecto que afirma que: "Si conociéramos mejor el siglo XVI ... ya no discutiríamos el problema de la globalización como si ésta fuera un fenómeno nuevo y reciente" y continúa con un juicio que podría poner en duda muchos de los planteamientos que al respecto se han realizado: "Desde el Renacimiento, la expansión de occidente ha producido híbridos por todo el mundo, al mismo tiempo que genera reacciones de rechazo". Con ello Gruzinsky pasa a articular su planteamiento acerca de lo mestizo: "A lo largo del planeta, el fenómeno del mestizo aparece fuertemente ligado a los albores de la globalización económica que coronaron la segunda mitad del siglo XVI, un siglo que... fue el siglo ibérico por excelencia, así como nuestro siglo se ha convertido en el siglo norteamericano" (GRUZINSKI, 2002, p. 4).

En este sentido, hablar de identidad después de la modernidad es romper con todos los conceptos sólidos que se habían fundado en la tradición, (familia, estado, sindicato, sólo por mencionar algunos) y es romper también, con una identidad fundada en ellos. En los tiempos que corren, en lo que Sygmunt Bauman llamaría la "modernidad líquida", la identidad es algo que desaparece en la medida que se disuelve el Estado-Nación, de ahí que él plantea que:

La identidad nacional concienzudamente construida por el Estado y sus organismos tiene por objetivo el derecho de monopolio para trazar el límite entre el nosotros y el ellos", es por ello, continua "que el concepto de 
identidad se ha vuelto completamente ambiguo, ... que sólo se esgrime en el contexto de un conflicto, en el campo de batalla: se trata de un concepto que, queriendo unir, divide, y queriendo dividir, excluye, de tal manera que, si alguna vez sirvió como estandarte para la emancipación, hoy puede resultar una forma encubierta de opresión." (BAUMAN, 2005, p. 54).

Como podemos apreciar bajo este concepto posmoderno de identidad el planteamiento de la existencia del arte latinoamericano como una unidad en sí misma, al igual que el arte de cualquier región del mundo, acaba por dejar de tener sentido. De este planteamiento se desprende que buscar una forma de encausar los intentos por plantear la existencia de un arte latinoamericano tendría que partir de establecer que ese "ser latinoamericano" es una forma de referirse a un lugar geográfico en que la pluralidad es de tal envergadura que pretender establecer esencias o naturalezas definidas se vería como un intento estéril, para no decir ingenuo.

En esta perspectiva, la naturaleza y lo propio de cada manifestación artística, de cada artista o de cada corriente, no se puede inscribir en una totalidad de lo latinoamericano. Esto es válido, a partir de la multiculturalidad que se vive en los propios países centrales, para Latinoamérica y para todas las regiones del mundo, Africa, el Medio y el Lejano Oriente, etc. Desde este punto de vista, la problemática que tiene como resultado la angustia de la identidad a la que se refería Morais, simplemente salta por los aires hecha mil pedazos, pues lo determinante ya no es entonces, el lenguaje artístico basado en una tradición lo que unifica al nosotros con respecto a los otros, sino que todos los individuos, en cuanto sujetos, nos constituimos en los otros con respecto a todos los otros. Y por ello, en este mundo de globalización económica, la aldea global de la que hablaba Marshall McLuhan, donde el único parámetro valorativo es la vorágine del mercado sin fronteras, las manifestaciones artísticas acuden al mercado de obras artísticas, que es la única forma en que pueden constatar la posibilidad de su existencia, simplemente como productos individuales, o como productos de un artista, o en su caso, como el producto de un artista que plantea en sus obras referentes estéticos propios de determinada corriente, que por cierto es lo más lejos que puede llegar el planteamiento colectivista.

Como puede verse esta visión en muchos aspectos está fuertemente permeada de un espíritu pesimista, donde el mercado se ve convertido en el único patrón de reconocimiento. Esta cuestión ya era planteada por Marta Traba en los años setenta, sin embargo, ella establecía como posibilidad de existencia del arte latinoamericano la resistencia. Resistencia que se enfrentaba desafiante al mundo del arte en los países desarrollados, que se caracteriza por ser una "producción incesante de arte de consumo, eliminación del concepto... que sirvió incondicionalmente a un proyecto imperialista destinado a descalificar las provincias culturales" (TRABA apud MORAIS, 1990, p. 9).

Por el contrario, bajo el concepto de identidad posmoderna que aquí he desarrollado, la resistencia que propone Traba, deja de tener sentido, pues la relación bipolar entre el imperio y la provincia deja de funcionar como eje rector de la crítica del arte. Ya no queda el nosotros que se resiste (Traba) o se libera (Morais) o que se traga al otro (Antropofagia) sino simplemente queda el individuo como tal. Este planteamiento nos puede llevar a una conclusión sumamente derrotista y probablemente es por ello que surge el escepticismo, y a veces la actitud cínica, que se transpira a través de este posicionamiento, pues bajo esta perspectiva en 
el mundo cultural y con ello, dentro del campo artístico, la ente identitaria definitoria ya no es el país, la región o el continente, sino lo único que ha quedado es el individuo posmoderno. Este, como fuerza individual acude al mercado a postular su quehacer artístico. Este individuo, si bien es cierto que está dotado de múltiples identidades, también, lo cual no deja de ser angustiante, en muchos aspectos se encuentra solitario en su incomunicable unicidad.

El plantear este tipo de identidad pluralista basada en una visión, que en los párrafos anteriores he llamado una identidad basada en el sujeto posmoderno, que buscaría conceptualizar al arte latinoamericano sin caer en una idea de la identidad ilustrada, ni una visión sociologista, nos lleva a plantear que probablemente también pudiera existir una visión optimista de ella. Alguna tentativa conceptual podría salir de ese pesimismo si partiera de conceptualizar a los distintos individuos como unicidades identitarias que poseen determinados rasgos e intereses comunes que podría posibilitar en este mundo multicultural el enmarcarlos, no por su identidad adscrita a un país o a un continente, sino como conformadores de constelaciones conceptuales.

Una tentativa que podría ir en este sentido es la hace Mari Carmen Ramírez en su texto que llama "Reflexión heterotrópica: las obras" (RAMÍREZ, 2000). Sin que yo pretenda afirmar que la elaboración conceptual y la experiencia curatorial de Heterotopías, medio siglo sin lugar: 19181968, de Mari Carmen Ramírez se funda íntegramente en una idea de identidad posmoderna tal como aquí se le ha entendido, sí me atrevo a decir que muchos de los planteamiento que ahí se hacen tienen rasgos de esta visión de la identidad.

Mari Carmen Ramírez en esta experiencia curatorial organiza la ex- posición en siete constelaciones articuladas en torno a criterios conceptuales que condensan aspectos críticos -tanto ideológicos y formales- del desarrollo de las vanguardias latinoamericanas. Esas constelaciones son: Promotora, Universalista-Autóctona, Impugnadora, Cinética, Constructiva, Óptico-Háptica, Conceptual. Según ella: "Cada una de estas configuraciones está concebida como una categoría abierta y flexible capaz de relacionar, en un mismo espacio crítico y museográfico, a artistas, obras, estilos y temporalidades dispares" A continuación establece: "La utilidad de las constelaciones... radica en que ellas trascienden tanto las lecturas fragmentadas elaboradas a nivel nacional como la absurda desintegración de nuestros perímetros regionales". Posteriormente se hace la pregunta central para el efecto de nuestro ensayo: " ¿Existe, de hecho, lo latinoamericano...?" Y a continuación ella misma responde: "Difícil pregunta, imposible de ser respondida sin caer en absolutos o esencialismos improbables" (RAMÍREZ, 2000, p. 25).

En ese sentido, lo que la muestra referida busca, según la autora, es escapar de forma deliberada al paradigma historicista con que siempre se ha pretendido encasillar lo mejor y más destacado de la producción artística en América Latina. Para ello la visión constelar que plantea, implica una configuración arbitraria de puntos de vista así como actitudes a menudo contradictorias o en abierta tensión. En este sentido para ella este sería el punto generador de su propuesta en que "desde la perspectiva de nuestro continente, afirma Ramírez, Heterotopías significa que las respuestas al modelo modernista inicial no tuvieron-lugar debido a la unilateralidad inflexible del eje hegemónico legitimador con sus reglas y axiología conocidas. $O$ sea, que sucedieron y tuvieron efecto SIN-LUGAR, pero sólo con respecto a la 
lectura eurocentrada de Occidente o ensimismada de los Estados Unidos, que es lo mismo" (Idem, 23).

Como puede verse esta posibilidad de considerar a la América Latina como el no-lugar tiene una fuerte connotativa que considera a la identidad en el sentido más plural del término, esto es, como dijimos anteriormente, fundamentado en una visión no esencialista, sino pluralista de la identidad al afirmar la heterogeneidad y la contradictoriedad de la identidad cultural con lo que se estaría aseverando que no hay culturas uniformes. Lo que existen, en todo caso, son rasgos de identidad que nos van a permitir entender las respuestas contradictorias que cada sujeto puede dar, tanto individual como colectivamente, a cierta situaciones y problemas.

\section{A manera de conclusión}

Sin haber pretendido agotar la discusión con respecto a la problemática de la identidad artística en América Latina a partir de estas tres conceptualizaciones que se fundamentan en tres visiones del sujeto social, como ya lo mencioné: la ilustrada, la sociológica y la posmoderna, me parece que se puede ir estableciendo parámetros de análisis que permitan entender cuáles son los elementos conceptuales en las diferentes líneas de reflexión con respecto a esta temática, que muchas veces no se encuentran explícitamente desarrollados en los discursos de críticos, pensadores, analistas y demás actores involucrados en dicha temática.

El localizar el concepto de identidad artística que se subsume en las diferentes perspectivas de comprensión acerca de la latinoamericanidad en el arte, permitiría, como una derivación teorética de ella, abordar, a través de este instrumental analítico, la problemática referida a los procesos y rutas que sigue el mecanismo de legitimación de la actividad creativa en general y de las obras artísticas en particular. Con ello se estarían abriendo caminos para proponer tentativamente postulados que podrían plantear la relación entre los criterios de legitimación y el tipo de identidad de referencia.

Bajo esta perspectiva se podría sugerir de manera preliminar que la identidad ilustrada basa sus criterios consagratorios en la integración de la obra artística a los valores canónicos europeo-norteamericanos externos a la realidad provincial latinoamericana; por su parte, la identidad sociologista, plantea que la legitimidad está dada en torno al proceso de lucha y subversión que el quehacer creativo lleva a cabo en contra de esos valores, y finalmente, la identidad posmoderna, sin perder la necesidad de constituirse como un elemento opositivo a ese canon, no hace de ello su única ruta, sino que recibe los estímulos del modelo central y los reprocesa, esto es, como dice Ramírez: "las utopías (como no-lugar) no valen por sí propias a no ser que estén invertidas, que sean posibles o bien que operen de modo reciclable". (RAMÍREZ, p. 23).

\section{Bibliografía:}

ACHA, Juan. In: DAMIÁN Bayón (ed.). El artista latinoamericano y su identidad. Caracas: Monte Ávila Editores, 1977.

ACHA, Juan. Problemas artísticos de América Latina. In: Arte, Historia e identidad en las Américas. México: I. I. E. UNAM. 1994.

AGUSTíN, José. La contracultura en México. México: Libro de Bolsillo, 2004.

BAUMAN, Zygmunt. Identidad. Buenos Aires: Losada, 2005. 
BUNTINX, Gustavo. El indio alfarero como construcción ideológica. Variaciones sobre un tema de Francisco Laso. In: Arte, Historia e identidad en las Américas. México: I. I. E. UNAM, 1994.

FOUCAULT, Michel. Las Palabras y las cosas. México: Siglo XXI, 1968.

GARCÍA CANCLINI, Néstor. Culturas híbridas. México: Grijalbo, 2003.

GIUNTA, Andrea. Strategies of Modernity in Latin America. In: MOSQUERA, Gerardo. Beyond the Fantastic. Londres: MIT Press, 1996.

GRUZINSKI, Serge. The mestizo mind. New York: Routledge, 2002.

GUTIÉRREZ, Roberto. Identidades políticas y democracia. México: IFE, 2001.

HERNÁNDEZ, Orlando. Mapa (incompleto) de Por América. In: Por América la obra de Juan Francisco Elso. México: I. I. E. UNAM, 2000.

MORAIS, Federico. Las artes plásticas en la América Latina: del trance a lo transitorio. Cuba: Casa de las Américas, 1990.

MOUFFE, Chantal. El retorno de lo político. Barcelona: Paidós, 1999.

PAZ, Octavio. Introducción. In: DAMIÁN Bayón (ed.). El artista latinoamericano y su identidad. Caracas: Monte Ávila Editores, 1977.

PAZ, Octavio. Los privilegios de la vista. In: México en la Obra de Octavio Paz. México: F.C.E., 1987.

RAMÍREZ, Mari Carmen. Reflexión heterotópica: las obras. In: Heterotopías medio siglo sin-lugar: 1918-1969. Madrid: Museo Nacional Centro de Arte Reina Sofía, 2000.

RICHARD, Nelly. La puesta en escena internacional del arte latinoamericano: montaje, representación. In: Arte, Historia e identidad en las Américas. México: I. I. E. UNAM, 1994. i Tomás Ejea Mondoza. Profesor-investigador de la Universidad Autónoma Metropolitana Unidad Azcapotzalco de la Ciudad de México. Contato: tomas. ejea@gmail.com

ii Aquí cabría hablar de la propuesta que Paz hace en El laberinto de la soledad acerca de los Pachucos y la crítica que José Agustín le plantea al respecto: "Octavio Paz,... los consideraba (a los pachucos) un extremo, clowns impasibles y siniestros, pasivos y desdeñosos, sadomasoquistas que pretendían aterrorizar y que en realidad sólo mostraban vocación de víctimas, para llamar la atención, o de delincuentes, para ser "héroes malditos". No contento con esta andanada de derechazos, don Octavio descalificó al pachuco como un ser inútil que no reivindicaba ni la raza ni la nacionalidad de sus antepasados, y cuya rebeldía era un "gesto suicida, pues el pachuco no afirma nada, no defiende nada, excepto su exasperada voluntad de no-ser"; es "una llaga que se muestra, una herida que se exhibe y que es adorno bárbaro, caprichoso y grotesco En efecto, eran una herida que se exhibía, pero Paz condenó la llaga y no el cuerpo enfermo en que había brotado. A fin de cuentas redujo un complejo fenómeno cultural a museo de horrores, y lo utilizó para tejer metáforas y ejercitar el estilo." (AGUSTíN, 2004, p. 19)

iii El concepto de posmodernidad es muy polémico pues en su discusión entrarían en juego términos como modernidad reflexiva, capitalismo tardío, etc. Para no entrar en una controversia teórica que rebasa los propósitos de este ensayo lo utilizaré en una de sus acepciones más simples, esto es, entender lo posmoderno como un planteamiento que se refiera a una etapa cronológica y formalmente posterior a la modernidad tardía.

\section{Recebido em 20/07/2015 Aprovado em 31/07/2015}

